\title{
O MOMENTO PERICIAL - ETHOS PERICIAL E DISPUTAS NO CAMPO PREVIDENCIÁRIO - RESULTADOS PRELIMINARES ${ }^{1}$
}

\section{Leonardo Biscaia ${ }^{2}$}

- Enviado em 19/01/2016

- Aprovado em 08/02/2016

Esta pesquisa tem três objetivos principais, quais sejam, o teste das hipóteses mencionadas abaixo, a descrição de um campo social (o previdenciário) e o estudo do habitus da perícia médica previdenciária e a sua inserção no campo previdenciário.

Esses objetivos são perseguidos a partir da teoria dos campos de Pierre Bourdieu, estrutura conceitual apropriada para a apreensão das várias dimensões explicativas da ação social do perito médico: o Welfare State, a previdência social brasileira, as diferentes racionalidades burocráticas, as diferenças entre o perito médico e seus pares assistentes. Recupera-se a historiografia tanto da seguridade social brasileira quanto da perícia médica brasileira e procura-se explicar como esta se insere naquela. Além disso, como a função precípua do perito médico previdenciário é avaliar a capacidade para o trabalho de segurados do regime geral da previdência social, discute-se a sociologia do usuário da previdência social e o processo saúde-doença do segurado da previdência. O habitus e o ethos do perito médico são perscrutados por pesquisa empírica que analisa seus valores e suas posturas sobre a previdência social, sobre os segurados, sobre si mesmos e sobre os outros agentes do campo. Para tentar evidenciar o que há de específico no habitus pericial, deu-se atenção também para os valores dos demais servidores da previdência social brasileira, genericamente denominados de "administrativos", em contraposição aos peritos médicos.

\footnotetext{
${ }^{1}$ Pesquisa de doutoramento em andamento sob a orientação da Professora Doutora Maria Tarcisa da Silva Bega no Programa de Pós-graduação em Sociologia da UFPR.

2 Graduado em Medicina pela UFPR. Mestrado em Saúde Pública pela Fiocruz. Endereço eletrônico: leonardobiscaia@hotmail.com
} 
A enorme estrutura de seguridade social e, mais especificamente, de previdência social, corresponde a uma complexa rede de relações sociais envolvendo inúmeros agentes individuais e coletivos que constitui o que denominamos de campo previdenciário. Desse campo se sabe quais as quantias envolvidas, as suas fontes de arrecadação, os resultados das políticas de seguridade para os grupos aos quais se destinam e quem são as pessoas que mais se beneficiam das ações públicas. Entretanto, ainda não se conhece o papel desempenhado pelos médicos peritos da previdência social em detalhes, como se dá o seu recrutamento, qual é o seu habitus e quais os processos de incorporação desse habitus pelos médicos. As informações existentes sobre a perícia médica ultrapassam em pouco a cobertura jornalística, habitualmente abordando a fila para a perícia médica do INSS (Instituto Nacional do Seguro Social), movimentos paredistas etc. De modo geral são notícias que exploram o argumento do espantalho partindo de lugares comuns igualmente baseados em descrições do tipo espantalho; essas descrições não infrequentemente são usadas com fins políticos, inclusive por grupos ligados à esquerda brasileira.

\section{Hipóteses}

Usamos alguns pressupostos teóricos que foram postos à prova ao longo das investigações; eles são os seguintes: a perícia médica previdenciária ocupa um locus específico dentro do sistema de seguridade social e apresenta traços muito distintos dos demais médicos "tradicionais". A sua função explícita consiste basicamente na avaliação da capacidade para o trabalho exibida pelos usuários do INSS segundo o que a legislação previdenciária estabelece. Por outro lado, esse papel pode ser entendido como gatekeeper da previdência social, isto é, o de fazer a triagem do que a literatura chama de caronistas e míopes. O exercício dessas funções supõe a existência de um determinado poder sobre a vida dos cidadãos que rompe com o papel de doente (sick role) desempenhado pelo segurado e com as expectativas que acompanham o papel de doente. A relação entre o perito médico previdenciário e o usuário da previdência, portanto, tem uma natureza essencialmente conflituosa.

A quantidade de capital simbólico que a perícia tem ao seu dispor dentro do campo previdenciário é desproporcionalmente inferior à sua importância relativa dentro desse mesmo campo, cada vez maior, e a autarquia atua no sentido de frear os esforços da perícia médica em aumentar o seu capital disponível. 
O habitus da perícia médica previdenciária desenvolve-se a por meio do processo de transformação de médico em burocrata de nível de rua, pela rotina de atendimento dos segurados e pelo relacionamento com os servidores administrativos.

\section{Trajetória da pesquisa}

A partir da teoria dos campos de Pierre Bourdieu (2009) procurou-se caracterizar o que denominamos de campo previdenciário, descrevendo os seus agentes, suas relações recíprocas e as formas como disputam as diversas formas de capital, notadamente o simbólico. O agente coletivo perícia médica previdenciário naturalmente foi estudado com mais vagar por ser o objeto da pesquisa.

A descrição do campo previdenciário usou uma abordagem ao mesmo tempo histórica, teórica e empírica, iniciando-se pelo contexto sociológico dentro do qual a perícia médica insere-se, isto é, o Welfare State, e continuando com o Estado do Bem-Estar Social brasileiro, a sociologia da burocracia e da burocracia do nível de rua e a sociologia do papel do doente. O conceito de burocracia do nível de rua foi tomado da obra de M. Lipsky (1980) e o papel de doente é o descrito por T. Parsons (1951). A atividade da perícia consiste na análise de requerimentos de benefícios concedidos para os segurados do INSS; as suas relações com esse grupo altamente heterogêneo permitem compreender muitos aspectos do habitus e do ethos dos peritos, justificando que se esmiuçasse quem é o segurado da previdência social e o que o leva a requerer benefícios previdenciários.

A caracterização do habitus do perito médico previdenciário que procuramos fazer deu-se usando algumas estratégias complementares; a mais óbvia foi a consulta dos textos sociológicos sobre os diversos assuntos tratados nesta tese. Outra estratégia constitui-se na aplicação de questionários de múltipla escolha enviados por e-mail aos servidores do INSS. Usou-se a plataforma de pesquisas na internet Surveymonkey para construí-los, enviá-los por email e registrar as respostas. A ordem precisa das questões, o número de opções disponíveis e o tipo do questionário seguiram as sugestões de GÜNTHER (2003). As questões formuladas eram do tipo escala "discordo totalmente-concordo totalmente". Cada respondente tinha que dar o consentimento expresso de sua participação na pesquisa e da utilização de suas respostas para esta pesquisa. Em seguida os dados coletados foram analisados por meio do programa SPSS versão 20; os testes estatísticos foram 
descritivos (médias e desvios-padrão) e a análise de variância (ANOVA), admitindo-se $\mathrm{p}<0,01$ e intervalo de confiança de $99 \%$.

O formulário foi construído a partir de dois expedientes básicos. Em primeiro lugar, fez-se a revisão da literatura sociológica a respeito da profissão médica, da perícia médica previdenciária e da seguridade social como um todo. Depois os principais aspectos da teoria sociológica e dos achados empíricos descritos na literatura foram levantados, procurou-se destacar, dentre eles, quais se relacionariam com os objetivos da pesquisa e com seu objeto. Um formulário preliminar, exploratório, foi construído e aplicado a peritos selecionados da GEx Curitiba (Gerência Executiva do INSS em Curitiba); nesse primeiro questionário os peritos eram instados a manifestar suas opiniões pessoais longamente, fazendo quaisquer considerações que julgassem relevantes. Procuramos definir categorias empíricas a partir da análise desses questionários exploratórios, contrapondo-as às que obtivemos com a pesquisa dos textos sociológicos sobre o assunto. Detivemo-nos nos assuntos comentados mais amiúde, nas respostas desenvolvidas mais minuciosamente e nos temas que julgamos ter sido deixado de lado, articulando com a importância relativa dada pela literatura sociológica.

Diante disso, procurou-se desenvolver os aspectos menos contemplados pelos peritos ao mesmo tempo em que se buscou esmiuçar aqueles que foram objeto da atenção tanto dos textos quanto dos peritos. Isso foi possível pelo tipo das perguntas feitas no questionário final e pela sua quantidade em cada assunto. As perguntas articularam-se em torno das seguintes categorias empíricas:

- Autonomia (perguntas que tratam da autonomia);

- Relacionamento entre peritos médicos e servidores administrativos;

- Relacionamento dos peritos médicos com colegas médicos, tanto peritos quanto assistente;

- Relacionamento dos peritos médicos com os segurados;

- Autoimagem dos peritos dentro do INSS e satisfação com o trabalho; e

- Perfil demográfico dos peritos médicos.

As questões dirigidas aos servidores administrativos objetivaram ser "um grupo controle" relativamente às dimensões comuns a todos os servidores do INSS:

- Relacionamento entre peritos médicos e servidores administrativos;

- Relacionamento dos servidores administrativos com os segurados; e 
- Autoimagem dos servidores administrativos dentro do INSS e satisfação com o trabalho; e

- Perfil demográfico dos servidores administrativos.

- Cada uma das questões foi analisada a partir das seguintes variáveis demográficas:

- Sexo;

- Faixa etária;

- Tempo de medicina (apenas para os peritos médicos);

- Tempo de INSS;

- $\mathrm{SR} ; \mathrm{e}$

- Setor dentro da APS onde trabalha (exclusivamente para os servidores administrativos).

Os resultados preliminares sugerem que a perícia médica previdenciária busca manter a dignidade e a autonomia do conteúdo de sua prática ao mesmo tempo em que se sujeita à subordinação hierárquica dentro de uma estrutura fortemente centralizada, em que representa apenas uma parte pequena, ainda que indispensável. Tal sujeição implica também o aprendizado de um habitus profundamente diverso daquele assumido pelo médico que intervém no processo saúdedoença assistindo os pacientes/usuários. Diferentemente dos médicos assistentes, os peritos médicos pautam sua prática mais no respeito à legislação e na análise biomédica do que em aspectos "sociais", como o acometimento por doenças estigmatizantes, sustentando empiricamente as oposições éticas dos peritos médicos e dos médicos assistentes apontadas pela literatura (ALMEIDA, 2011).

As racionalidades pericial e dos servidores administrativos distanciam-se muito a respeito de aspectos fundamentais, como por exemplo a postura que o funcionário público deve ter em relação ao usuário do INSS. Os servidores administrativos, de modo muito nítido, veem o requerente aos benefícios previdenciários segundo a moralidade do médico assistente, que associa a justeza da concessão do benefício à mera presença de doença ao invés de à incapacidade para o trabalho. Além disso, as diversas dimensões da autonomia profissional pertencentes ao ethos pericial conflitam com o entendimento que os servidores administrativos têm dela, no que são acompanhados por vários outros agentes coletivos do campo previdenciário, a exemplo das Juntas de Recursos da Previdência Social e do Ministério Público Federal. 


\section{REFERÊNCIAS:}

ALMEIDA, E.H.R. (2011). Aspectos bioéticos da perícia médica previdenciária. Revista Bioética, v. 19, n. $1, \quad$ p. 277-298. Disponível em: http://revistabioetica.cfm.org.br/index.php/revista_bioetica/article/view/618/637. Acesso em: 11.set.2011.

BOURDIEU, P. (2009). Coisas ditas. São Paulo: Brasiliense.

GÜNTHER, H. (2003). Como elaborar um questionário. Série Planejamento de Pesquisa nas Ciências Sociais, n. 1. Brasília: UnB.

LIPSKY, M. (1980). Street-Level Bureaucracy. Dilemmas of the Individual in Public Services. New York: Russell Sage Foundation.

PARSONS, T. (1951). The Social System. London: Free. 